\title{
Introduction: The Study of the Linguistic Landscape as a New Approach to Multilingualism
}

\author{
Durk Gorter \\ Fryske Akademy/Universiteit van Amsterdam, Amsterdam, \\ The Netherlands
}

Language is all around us in textual form as it is displayed on shop windows, commercial signs, posters, official notices, traffic signs, etc. Most of the time people do not pay much attention to the 'linguistic landscape' that surrounds them. However, in recent years an increasing number of researchers have started to take a closer look and study the language texts that are present in public space. This special issue of the International Journal of Multilingualism reports on a number of case studies around the world.

According to the dictionary, 'landscape' as a noun has basically two meanings. On the one hand the more literal meaning of the piece or expanse of scenery that can be seen at one time from one place. On the other hand, a picture representing such a view of natural inland scenery, as distinguished from sea picture or a portrait. In the studies of the linguistic landscape presented here, one can say that both meanings are also used. On the one hand the literal study of the languages as they are used in the signs, and on the other hand also the representation of the languages, which is of particular importance because it relates to identity and cultural globalisation, to the growing presence of English and to revitalisation of minority languages.

The concept of linguistic landscape, however, has been used in several different ways. In the literature the concept has frequently been used in a rather general sense for the description and analysis of the language situation in a certain country (e.g. for Malta by Sciriha \& Vassallo, 2001) or for the presence and use of many languages in a larger geographic area (e.g. the Baltic area by Kreslins, 2003). An overview of the languages that are spoken is then referred to as the linguistic landscape. In this more or less loose sense of the word linguistic landscape can be synonymous with or at least related to concepts such as linguistic market, linguistic mosaic, ecology of languages, diversity of languages or the linguistic situation. In those cases linguistic landscape refers to the social context in which more than one language is present. It implies the use in speech or writing of more than one language and thus of multilingualism.

Sometimes the meaning of linguistic landscape is extended to include a description of the history of languages or different degrees in the knowledge of languages. Or more narrowly, it can refer to language internal variation in parts of just one language, in particular in relation to its vocabulary, but also in 
other elements, even the words used in therapeutic communication (Fleitas, 2003). Sometimes it refers to the system of just one language, in other cases it indicates the spread and boundaries of dialects (Labov et al., 1997). Linguistic landscape has even been used for a count of non-English speakers in primary schools in California (Tafoya, 2002).

A meaning that comes closer to the way it is used here is in reference to signage and place-names as Hicks (2002) does for Gaelic in Scotland. He also mentions campaigns of overpainting of signs in Wales, which can be seen as a literal expression of the symbolic struggle for space for a language. The definition given by Landry and Bourhis (1997: 25) is followed by all authors in this issue:

The language of public road signs, advertising billboards, street names, place names, commercial shop signs, and public signs on government buildings combines to form the linguistic landscape of a given territory, region, or urban agglomeration.

Thus they are concerned with the use of language in its written form in the public sphere. It refers to language that is visible in a specified area (Bourhis \& Landry, 2002). The number of linguistic tokens is especially high in shopping areas in cities. Instead of calling it the linguistic landscape it could also be named linguistic cityscape. In this special issue of the International Journal of Multilingualism it will be used in the sense related to commercial signage and place names.

The four papers brought together in this special issue deal with the linguistic landscape in five different societies: Israel, Thailand, Japan, the Netherlands (Friesland) and Spain (the Basque Country). All of them focus on the linguistic landscape of the cities (and in that sense are more studies of cityscapes than of landscapes).

The study of the linguistic landscape is a relatively new development. It enjoys a growing interest in sociolinguistics and applied linguistics. Backhaus (this issue) has a series of references to recent studies of the linguistic landscape in various places around the globe.

The introduction of digital cameras with sufficient memory for a reasonable price allows researchers to take an apparently unlimited number of pictures of the signs in the linguistic landscape. The technique of taking large numbers of photographs of signs and of putting them in a database on a computer in itself is relatively uncomplicated. But a researcher who does data collection in the form of large numbers of photographs faces a number of general and some special problems. The methodology of this field still has to be developed further.

First of all there is the problem of sampling. Where do you take pictures and how many? Is representativity for a certain city, an area or even a whole country a point of consideration? It is very well possible for a researcher to limit himself to one city or area, as Huebner and Backhaus do in their study of the linguistic landscape of Bangkok and Tokyo, respectively. Inside those large metropolitan areas they had to make a further selection. Huebner took samples from 15 neighbourhoods in central and suburban Bangkok and Backhaus surveyed 28 streets in Tokyo near the 28 stations of the circular 
railroad line of the central city. Still, as Huebner states, the data are not meant to indicate the linguistic composition of the city as a whole, but simply as an illustration of the linguistic diversity. For Ben Rafael et al it was important to select localities which represent the ethnocultural and national divisions in Israeli society; thus they sampled four Jewish localities, three IsraeliPalestinian localities and one non-Israeli Palestinian locality. Their second step was to sample those parts of the cities where the major commercial activity takes place and the principal public institutions are located. They only sampled a limited number of all items in a specific site (30\% of public and $70 \%$ of commercial sites). In contrast, Backhaus only sampled those signs that were classified as multilingual (according to his definition) and thus sampled around $20 \%$ of the total of almost 12,000 signs that he counted. For Cenoz and Gorter, representativity was not the most important concern. They took one main shopping street in the major towns of the Basque Country and Friesland and used them as a case for the exploration of the linguistic landscape. They were careful to record a complete inventory of all texts to be seen on those streets.

The problem of sampling points to a further issue which turns out to be a rather complex problem, although on the face of it it may seem simple and straightforward. One may say that the linguistic landscape refers to linguistic objects that mark the public space. But the question is what constitutes such an object or sign? In other words, what constitutes the unit of analysis? Different answers can be given. It has to be determined what belongs to the linguistic landscape. For instance, are texts on moving objects such as buses or cars to be included? For convenience sake they are probably not. Although the landscape may change from day to day, some posters will be removed or added, but other signs may be fixed for many years. Backhaus defines his unit of analysis as 'any piece of text within a spatially definable frame' from small handwritten stickers to huge commercial billboards. Cenoz and Gorter decided in the case of shops, banks and other businesses to take all texts together as a whole and thus each establishment and not each individual sign became the unit of analysis.

The next step is the categorisation of the signs. Each of the researchers here distinguishes between top-down and bottom-up. That dimension refers to a difference between official signs placed by the government or related institution and nonofficial signs put there by commercial enterprises or by private organisations or persons. For each, a sign coding scheme has to be developed, where a researcher can decide to make it more or less elaborated. This scheme includes elements such as how language appears on the sign, the location on the sign, the size of the font used, the number of languages on the sign, the order of languages on multilingual signs, the relative importance of languages, whether a text has been translated (fully or partially), etc. Ben Rafael et al. have developed a coding scheme that contains 16 variables; this scheme was also applied by Cenoz and Gorter.

The characteristics thus coded can be quantified and analysed. The theoretical framework in which the analyses are done differs among the studies presented here. The approach still has to be developed further. As said, the dimension of official or governmental versus nonofficial or nongovern- 
mental is common to all articles because it indicates important languagerelated differences for the signs placed in the linguistic landscape. Ben Rafael et al. demonstrate the usability of existing sociological theories for the analysis as they make use of the work of Boudon, Bourdieu and Goffman. In his paper Huebner takes a more (socio)linguistic approach in which he looks in particular at phenomena of language mixing and language contact.

Issues which are not raised in the papers presented here, but which can also be of importance to the study of the linguistic landscape can be found in related branches of knowledge, such as psychological experiments in visual perception, studies of cityscapes in cultural geography and approaches to design and aesthetics. These will be left for future studies.

\section{Overview of the Issue}

The cultural, socioeconomic and political circumstances in the cities and the countries in which the studies are located, are quite divergent. On the one hand, multimillion cities are included such as Bangkok and Tokyo, on the other hand are small cities such as Ljouwert-Leeuwarden (less than 100,000 inhabitants) and Donostia-San Sebastian (around 200,000 inhabitants). At the same time the effect of globalisation, which might also be referred to as McDonaldisation of the linguistic landscape (Heller, 2003), has affected each case, which is reflected in the increasing space of the English language.

The paper by Ben Rafael, Shohamy, Amara and Trumper-Hecht compares patterns of linguistic landscape in a number of Israeli cities and small towns, and in East Jerusalem.

Of the eight localities, some are homogeneous and others mixed in terms of the groups that were studied. The study focuses on the degree of visibility on private and public signs of the three major languages: Hebrew, Arabic and English. There are different patterns in the various communities: Hebrew/ English signs prevail in Jewish communities; Arabic/Hebrew in IsraeliPalestinian communities and Arabic/English in East Jerusalem.

Further analysis also gives expression to differences between public (topdown) and private (bottom-up) signs. Taken together the linguistic landscape is not a true reflection of the diversity of Israel's languages. Three sociological perspectives are used to develop a number of research questions. It is hypothesised that the linguistic landscape should be explainable in terms of power relations between dominant and subordinate groups. Further that identity markers of communities would imprint themselves strongly on the linguistic landscape and finally, that different languages vary in attractiveness to different audiences. It is in this perspective that they speak of linguistic landscape in terms of symbolic construction of the public space.

Bangkok, a major city in Thailand, South East Asia, is the background of Huebner's study. He examines questions of language mixing and language dominance. He studies the linguistic landscape of 15 different neighbourhoods. By comparing the various neighbourhoods he makes visible the linguistic diversity in a large metropolitan area like Bangkok. He also provides a linguistic framework for the analysis of different types of codemixing. English as a global language turns out to have an important influence. He 
offers evidence of a shift from Chinese to English as the major language of wider communication in the city. From a linguistic perspective, the paper documents the influence of English on Thai, the state language, not just in the form of lexical borrowing, but also in aspects of orthography, pronunciation and syntax. At the same time, his study supplies proof of an emerging Thai variety of English. From an applied perspective, the data presented raise questions about the effects of the pervasiveness of English in the linguistic landscape of Bangkok on the language proficiency, both Thai and English, of its youngest citizens.

Also in Asia, but in quite a different socioeconomic context, the paper by Backhaus deals with multilingual signs in Tokyo, the Japanese capital. In his empirical study special attention is given to the distinction between official and nonofficial multilingual signs. He wants to shed some light on the relationship between two types of multilingual signs in Tokyo. It is demonstrated that the two types of signs show different characteristics with regard to the languages used and how they are arranged on the signs. The notions of power and solidarity are used to interpret the differences. Official signs do mainly express and reinforce existing power relations in Japan, but nonofficial signs make more use of foreign languages, mainly English, to communicate solidarity with non-Japanese things. Backhaus explicitly establishes links between his study of the linguistic landscape in Tokyo and the growing corpus of linguistic landscape research around the world.

The final paper by Cenoz and Gorter compares two regions in Europe. The authors examine the linguistic landscape in Friesland (the Netherlands) and the Basque Country (Spain). An analysis is given of the use of the minority language (Basque or Frisian), the state language (Spanish or Dutch) and English as an international language. Their study focuses on two streets in two multilingual cities where the minority language, Frisian or Basque, is in use. They compare both situations for the presence of the minority languages in the linguistic landscape as it relates to differences in language policy, as well as to differences in the spread of English. The data of language signs are analysed to determine the number of languages used, which languages are on the signs and the specific characteristics of bilingual and multilingual signs. Their findings show that the official language policy regarding minority languages is reflected in the linguistic landscape, but at the same time that there are important differences between both regions.

\section{References}

Bourhis, R.Y. and Landry, R. (2002) La loi 101 et l'aménagement du paysage linguistique du Quebec. In P. Bouchard and R.Y. Bourhis (eds) L'aménagement Linguistique au Québec: 25 D'application de la Charte de la Lange Francaise (pp. 107-132). Québec: Publications du Québec.

Fleitas, J. (2003) The power of words: Examining the linguistic landscape of pediatric nursing. American Journal of Maternal Child Nursing 28 (6), 384-388.

Heller, M. (2003) Globalization, the new economy and the commodification of language. Journal of Sociolinguistics 7 (4), 473-492.

Hicks, D. (2002) Scotland's linguistic landscape: the lack of policy and planning with Scotland's place-names and signage. Paper at World Congress on Language Policies, 
Barcelona 16-20 April 2002. On WWW at www.linguapax.org/congres/taller/ taller2/Hicks.html. Accessed 03.01.05.

Kreslins, J. (2003) Linguistic landscapes in the Baltic. Scandinavian Journal of History 28 (3-4), 165-174.

Labov, W., Ash, S. and Boberg, C. (1997) A National Map of The Regional Dialects of American English. On WWW at www.ling.upenn.edu/phono_atlas/NationalMap/ NationalMap.html. Accessed 03.01.05.

Landry, R. and Bourhis, R.Y. (1997) Linguistic landscape and ethnolinguistic vitality: An empirical study. Journal of Language and Social Psychology 16, 23-49.

Sciriha, L. and Vassallo, M. (2001) Malta: A Linguistic Landscape. Malta: University of Malta.

Tafoya, S.M. (2002) The linguistic landscape of California schools. California Counts 3 (4), 1-14. 